\title{
EFISIENSI USAHATANI TUMPANG SARI JAGUNG \\ (Zea mays, L.) DAN KACANG TANAH (Arachis \\ hypogaea, L.) DI LAHAN TANAMAN JATI (Tectona \\ grandis, L. F.) MILIK PERUM PERHUTANI PADA \\ KELOMPOK TANI MAJU TANI
}

\author{
Dede Nurmelyana $^{1}$, Teguh Iman Santoso ${ }^{2}$, Neneng Sri Mulyati ${ }^{3}$ \\ 1,2,3 Program Studi Agribisnis, Fakultas Pertanian, Universitas Wiralodra \\ E-mail : dedenurmelyana3@gmail.com¹, teguhimans@ unwir.ac.id², nenengsrimulyati44@ gmail.com³
}

\begin{abstract}
ABSTRAK
Penelitian ini bertujuan untuk mengetahui besarnya biaya produksi, keuntungan, nilai R/C dan Rentabilitas usahatani Tumpangsari Jagung dan Kacang Tanah pada Lahan Perum Perhutani. Desain yang digunakan adalah desain penelitian survei deskriptif, dan metode yang digunakan dalam penelitian ini adalah survei dengan jumlah responden seluruhnya adalah 11 orang diambil dari populasi Kelompok Tani Maju Tani yang berusahatani Jagung dan Kacang Tanah secara Tumpangsari. Berdasarkan hasil penelitian dengan luas rata-rata $0,5 \mathrm{Ha}$, diperlukan biaya usahatani sebesar Rp. 3.942.162,88 untuk jagung dan Rp. 3.881.032,60 Untuk Kacang Tanah. Besarnya rata-rata keuntungan usahatani jagung dan kacang tanah per luas lahan garapan adalah sebesar Rp. 3.181.746,21 untuk jagung dan Rp. 3.989.421,95 untuk kacang tanah. Nilai R/C untuk Jagung adalah sebesar 1,80 dan 1,95 untuk kacang tanah. Rentabilitas Usahatani Jagung adalah $80 \%$ dan $95 \%$ untuk kacang tanah.
\end{abstract}

Kata kunci : Efisiensi, Usahatani, Tumpangsari, Lahan. 


\section{I.PENDAHULUAN}

Sektor pertanian dan pangan sangat penting dalam pembangunan nasional. Keadaan ini dapat dilihat dari berbagai hal investasi disektor pangan yang dilakukan pemerintah. Seperti investasi pemerintah disektor pertanian dan perairan, penelitian dan mengembangkan teknologi dibidang usaha tani maupun kebijakan harga. Investasi tersebut salah satunya menyediakan pangan yang merata serta dapat mudah terjangkau oleh masyarakat (Soekartawi, 2002). Pembangunan pertanian dapat meningkatkan taraf hidup petani terurata pada pendapatan melalui terbukanya lapangan pekerja dan kesempatan berusaha untuk mencapai kesejahteraan rakyat secara luas dan merata khususnya masyarakat Desa Cikawung Kecamatan Terisi Kabupaten Indramayu. Usahatani hortikultura berupa buah-buahan dan sayuran menjadi salah satu alternatif utama guna mengoptimalkan penggunaan lahan pertanian yang kurang produktif khususnya pada lahan Perum Perhutani yang dilihat keadaan kondisi tanahnya tidak rata, dan juga mengandalkan sistem pengairannya tadah hujan.

Masyarakat Desa Cikawung memanfaatkan lahan Perum Perhutani untuk menanam Jagung dan Kacang Tanah dengan sistem tumpangsari di antara tanaman pokoknya yaitu jati. Adanya tanaman selingan ini sebenarnya bermanfaat bagi pihak Perum Perhutani karena dapat mengurangi pekerjaan dalam pengendalian gulma pada tanaman jati yang semestinya dikerjakan oleh petugas Perum Perhutani. Maka dengan adanya petani yang menggarap atau menanam Jagung dan Kacang Tanah pada lahan Perum Perhutani, petanilah yang membersihkan gulma. Komoditas Jagung mempunyai fungsi multiguna dan strategis dalam pembangunan pertanian serta perekonomian di Indonesia, (Rukmana, 2010). Peran Jagung dalam ekonomi nasional, khususnya di pedesaan, juga sangat penting. Saat ini, konsums jangung didalam rumah tangga menduduki peringat terbesar kedua setelah padi yaitu 6,71 juta KK (37,63\%) dari 17,83 juta KK padi, palawija dan tebu (Departemen Pertanian, 2012)

Tanaman Kacang Tanah merupakan bagian yang tidak terpisahkan dari kebutuhan konsumsi masyarakat bahkan dunia dan sangat penting untuk dikembangkan guna menunjang perekonomian nasional. Tanaman Kacang Tanah pada lahan Perum Perhutani mulai dibudidayakan oleh petani, karena tanaman Kacang Tanah ini merupakan bahan kebutuhan yang harus memenuhi kebutuhan masyarakat, Kacang Tanah merupakan salah satu tanaman yang sangat prospektif dan handal, karena Kacang Tanah mempunyai nilai ekonomi yang tinggi (Jaelani, 2018). Kacang Tanah menjadi komoditas terpenting setelah komoditas kedelai di Indonesia.

Tumpang sari adalah pola menanam dengan dua atau lebih jenis tanaman pada satu areal lahan dalam waktu bersamaan. Sebagian besar tumpang sari dilakukan yaitu dengan penanaman dua jenis tanaman yang hampir sama secara bersamaan, seperti Jagung dan kedelai atau Jagung dan Kacang Tanah. Dalam kepustakaan, hal ini Dikenal sebagai double-Cropping. Tupang gilir merupakan pola tanam yang dilakukan setelah tanaman yang ertama panen. Pola Tumpang sari dapat dilakukan dengan menanam tanaman musiman (Zea mays, L.). Kacang-kacangan dapat menangkap nitrogen bebas dari udara bebas sehingga dapat memenuhi jika terjadi kekurangan oksigen(Warsana, 2009).

Peningkatan pendapatan petani dapat dilakukan dengan memanfaatkan lahan Perum Perhutani yang kosong atau disela-sela tanaman pokok yang biasa dinamakan tumpangsari. Tanaman Kacang Tanah dapat dilakukan dengan sistem pola tanam tumpangsari pada lahan kelompok tani di desa tersebut. Berdasarkan latar belakang tersebut maka perlu dilakukan penelitian mengenai Efisiensi Usahatani Tumpangsari Jagung (Zea mays, L.) dan Kacang Tanah (Arachis hypogaea, L.) di lahan tanaman Jati (Tectona grandis, L. F.) milik Perum Perhutani pada kelompok tani Maju Tani Desa Cikawung Kecamatan Terisi Kabupaten Indramayu Musim Tanam 2018/2019. 


\section{II.METODE PENELITIAN}

\section{Lokasi dan Jadwal Penelitian}

Penelitian telah dilaksanakan di Kelompok Tani Maju Tani Desa Cikawung Kecamatan Terisi Kabupaten Indramayu. Pemilihan Desa Cikawung sebagai objek penelitian dengan Pertimbangan bahwa di desa tersebut terdapat petani Jagung dan Kacang Tanah dengan sistem tumpangsari dengan pohon jati pada lahan Perum Perhutani.Teknik Pengumpulan Data Teknik pengumpulan data penelitian dilakukan di lapangan dan studi pustaka (literatur). Teknik pengumpulan data primer diperoleh dari lapangan dengan cara :

a Observasi yaitu teknik data dengan melakukan pengamatan langsung ke lapangan, dalam hal ini observasi dilakukan untuk mengumpulkan data kondisi objektif daerah penelitian.

b. Wawancara yaitu pengumpulan data dengan tanya jawab kepada responden, untuk mengetahui analisa usahatani Jagung dan Kacang Tanah.

Teknik pengumpulan data sekunder diperoleh dengan cara mengumpulkan data yang bersumber dari literatur berupa hasil penelitian, buku sesuai dengan topik penelitian.

\section{Populasi dan Sampel}

Jumlah anggota kelompok tani Maju Tani sebanyak 25 orang. 25 orang tersebut terdiri dari 11 orang yang menanam menggunakan metode tumpangsari antara jagung dan kacang tanah pada saat musim tanam 2018/2019, 5 orang menanam kacang tanah, 4 orang menanam jagung, sedangkan 5 orang hanya menanam padi. Sehingga dalam penelitian ini menggunakan tehnik purposive sampling yaitu menjadikan 11 orang yang menanam tumpangsari jagung dan kacang tanah sebagai sampel penelitian ini.

\section{Rancangan Analisis Data}

Analisis data yang akan digunakan dalam penelitian ini yaitu :

1. Besarnya biaya total (Total Cost $=$ TC) usahatani Jagung dan Kacang Tanah dengan rumus (Hernanto, 1989) :

$\mathrm{TC}=\mathrm{FC}+\mathrm{VC}$

Keterangan :

$\mathrm{TC}=$ Biaya Total $/$ Total Cost $(\mathrm{Rp}) \mathrm{FC}=$ Biaya Tetap $/$ Fixed Cost $(\mathrm{Rp})$

$\mathrm{VC}=$ Biaya Variabel $/$ Variable Cost $(\mathrm{Rp})$

2. Besarnya penerimaan total (Total Revenue $=\mathrm{TR}$ ) usahatani dapat dihitung dengan rumus (Hernanto, 1989):

$\mathrm{TR}=\mathrm{Y} . \mathrm{Hy}$

Keterangan :

$\mathrm{TR}=\quad$ Total Revenue $\quad$ (Penerimaan Total, $\mathrm{Rp})$

$\mathrm{Y}=$ Hasil Produksi $(\mathrm{Kg}) \mathrm{Hy}=$ Harga $(\mathrm{Rp} / \mathrm{Kg})$

3. Besarnya keuntungan atau pendapatan usahatani Jagung dan Kacang Tanah ditentukan dengan rumus (Hernanto, 1989):

$\pi=T R-(F C+V C)$

Keterangan :

$\Pi \quad=$ Keuntungan (Rp)

$\mathrm{TR}=$ Total Revenue (Penerimaan Total, Rp)

$\mathrm{FC}=$ Fixed Cost $($ Biaya Tetap, $\mathrm{Rp}) \mathrm{VC}=$ Variable Cost $($ Biaya Variabel, $\mathrm{Rp})$ 
4. Besarnya R/C rasio usahatani Jagung dan Kacang Tanah ditentukan dengan rumus (Hernanto, 1989)

$\mathrm{R} / \mathrm{C}=\frac{\mathrm{y} \cdot \mathrm{Hy}}{\mathrm{TC}}$

Keterangan :

$\mathrm{Y}=$ Jumlah Satuan produk yang dihasilkan $(\mathrm{Kg})$

$\mathrm{Hy}=$ Harga satuan produk yang dihasilkan $(\mathrm{Rp} / \mathrm{Kg})$

$\mathrm{TC}=$ Biaya Total

Jika nilai $\mathrm{R} / \mathrm{C}>1$ ( lebih dari 1) maka menguntungkan, jika niali $\mathrm{R} / \mathrm{C}<1$ (kurang dari 1) maka rugi, jika nilai $\mathrm{R} / \mathrm{C}=1$ maka impas.

5. Besarnya rentabilitas usahatani Jagung dan Kacang Tanah ditentukan dengan rumus (Hernanto, 1989):

$\mathrm{R}=\frac{\pi}{\mathrm{TC} \mathrm{x}} \times 100 \%$

$\mathrm{R}=$ Rentabilitas $(\%)$

$\pi=$ Keuntungan $(\mathrm{Rp})$

$\mathrm{TC}=$ Biaya Total $(\mathrm{Rp})$

Jika nilai rentabilitas > (lebih dari) bunga bank, maka layak untuk diusahakan. Jika nilai rentabilitas $<$ (kurang dari) bunga bank, maka tidak layak untuk diusahakan. Rentabilitas

\section{III.Hasil Dan Pembahasan}

\section{Biaya Total}

Biaya total merupakanpenjumlahan antara biaya tetapdan biaya variabel. Besarnya biaya total rata-rata usahatani Jagung dan Kacang tanah dapat dilihat pada tabel 16 dan tabel 17.

\section{Biaya Total Usahatani Jagung}

Berikurt ini adalah biaya total rata-rata untuk usahatani jagung.Untuk lebih jelasnya dapat dilihat di bawah ini.

Tabel 1. Biaya Total Rata-rata Usahatani Jagung

\begin{tabular}{clcc}
\hline No & Komponen Biaya Besar & Biaya (Rp) & Persentase (\%) \\
\hline 1 & Biaya Tetap & $515.117,43$ & 1,74 \\
2 & Biaya Variabel & $3.427,45$ & 85,26 \\
& Jumlah & $3.942 .162,88$ & 100,00 \\
\hline
\end{tabular}

Dari tabel 1 di atas terlihat bahwa jumlah biaya total rata-rata usahatani jagung adalah sebesar Rp. 3.942.162,88

Tabel 2. Biaya Total Rata-rata Usahatani Kacang Tanah.

\begin{tabular}{ccc}
\hline No & Komponen Biaya & Besar Biaya (Rp) \\
\hline 1 & Biaya Tetap & $531.078,06$ \\
2 & Biaya Variabel & $3.349 .954,55$ \\
& Jumlah & $3.881 .032,60$ \\
\hline
\end{tabular}




\section{Produksi, Harga dan Penerimaan}

Penerimaan, dan harga penerimaan hasil penelitian adalah sebagai berikut:

- Hasil Produksi jagung rata-rata 23,75 Kw/ Ha artinya hasil dari petani responden, sedangkan hasil produksi kacang tanah rata-rata $15,74 \mathrm{Kw} / \mathrm{Ha}$.

- Harga Jual Jagung rata-rata Rp. 300.000,00,-/Kw, sedangkan harga jual kacang tanah rata-rata Rp. $500.000,00,-/ \mathrm{Kw}$, artinya harga rata rata tersebut sudah ditentukan oleh pembeli/tengkulak dari jumlah petani.

- Hasil Penerimaan Jagung jumlah rataratanya adalah Rp. 7.123.909,09,- sedangkan hasil penerimaan Kacang tanah jumlah rata-ratanya adalah $\mathrm{Rp}$. 7.870.454,55,-. Hasil penerimaan tersebut berasal dari hasil perkalian antara produksi dan harga jual.

\section{Keuntungan}

Nilai keuntungan usahatani adalah nilai yang diterima umumnya dipengaruhi oleh factor biaya, hasil atau produksi yang diperoleh dan harga jual komoditas.Makin tinggi biaya produksi makin sedikit keuntungan yang diterima, sedangkan makin besar hasil atau produksi dan tingginya harga jual maka semakin besar keuntungan yang diperoleh. Keuntungan adalah penerimaan dikurangi biaya total yang dikeluarkan. Rata - rata hasil keuntungan usahatani jagung dapat dilihat pada tabel 18 di bawah ini.

Tabel 3. Rata-rata Hasil Keuntungan Usahatani Jagung

\begin{tabular}{clcc}
\hline No & Uraian & Nilai (Rp) & Persentase (\%) \\
\hline 1 & Penerimaan Total & $7.123 .909,09$ & 64,37 \\
2 & Biaya Total & $3.942 .162,88$ & 35,63 \\
& & $3.181 .746,21$ & 100,00
\end{tabular}

Rata-rata hasil keuntungan usahatani kacang tanah dapat dilihat pada tabel dibawah ini.

Tabel 4. Rata-rata Hasil Keuntungan Usahatani Kacang Tanah.

\begin{tabular}{cccc}
\hline No & Uraian & Nilai (Rp) & Persentase (\%) \\
\hline 1 & Penerimaan Total & $7.870 .454,55$ & 66,97 \\
2 & \multirow{2}{*}{ Biaya Total } & $3.881 .032,60$ & 33,03 \\
& & $3.989 .421,95$ & 100,00 \\
\hline
\end{tabular}

Dari tabel 3 dan tabel 4 di atas terlihat bahwa rata - rata hasil keuntungan usahatani untuk jagung adalah 3.181.746,21 dan rata - rata hasil keuntungan untuk kacang tanah yaitusebesar $3.989 .421,95$.

\section{Rasio Penerimaan Terhadap Biaya \\ Total $(\mathbf{R} / \mathbf{C})$}

Analisis efisiensi terhadap usaha tani dapat dihitung melalui revenue cost ratio $(\mathrm{R} / \mathrm{C})$ atau imbangan penerimaan dan biaya. Semakin tinggi nilai R/C maka semakin efisien usahatani tersebut. Berdasarkan hasil penelitian usahatani jagung pada lahan Perum Perhutani diperoleh keuntungan ratarata Rp 3.181.746,21 dengan biaya total 3.942.162,88 maka diperoleh nilai $\mathrm{R} / \mathrm{C}$ sebesar 1,80 artinya setiap 100 rupiah biaya yang dikeluarkan mendapat keuntungan 180. Sedangkan berdasarkan hasil penelitian usahatani kacang tanah pada lahan perhutani diperoleh keuntungan Rp. 3.989.421,95 dengan biaya total Rp. 3.881.032,60 maka diperoleh nilaiu R/C sebesar 1,95 artinya setiap 100 rupiah biaya yang dikeluarkan mendapat keuntungan 195 . 


\section{Rentabilitas}

Wijoyo (1983), bahwa usahatani menguntungkan secara ekonomis apabila nilai rentabilitas yang diterima oleh petani lebih tinggi dari tingkat suku bunga bank pada saat itu, untuk mengetahui rentabilitas dihitung dengan rumus rata-rata keuntungan dibagi dengan rata-rata biaya total dikali seratus persen $(100 \%)$. Perhitungan rentabilitas usahatani jagung pada lahan Perum Perhutani rata-rata sebesar $80 \%$.Sedangkan untuk usahatanikacang tanah pada lahan perum perhutani rata-rata sebesar 95\%. \lebih tinggi dari tingkat suku bunga Bank yang berlaku yaitu sebesar 18\% per tahun atau 3,5\% per 70 hari untuk jagung, dan $4 \%$ per 80 hari untuk kacang tanah. Dapat disimpulkan bahwa usahatani ini layak diusahakan secara ekonomis dapat dilihat pada lampiran 24 dan lampiran 25

\section{IV.KESIMPULAN}

\section{Simpulan}

Berdasarkan hasil pembahasan, maka kami menyimpulkan sebagai berikut :

1. Besarnya rata-rata biaya total usahatani Jagung dan Kacang tanah pada lahan Perum Perhutani per luas lahan garapan masing - masing (0,5 Ha) adalah Rp. 3.942.162,88 dan Rp. 3.881.032,60,-

2. Besarnya rata-rata keuntungan usahatani jagung dan kacang tanah per luas lahan garapan masingmasing (0,5 Ha) sebesar Rp. 3.181.746,21 dan Rp. 3.989.421,95., sedangkan besarnya penerimaan Usahatani Jagung dan Kacang tanah per luas lahan garapan $(0,5)$ masing-masing adalah sebesar Rp. 7.123.909,09 dan Rp 7.870.454,55

3. Besarnya efisiensi usahatani jagung dan kacang tanah pada lahan Perum Perhutani menguntungkan karena nilai $\mathrm{R} / \mathrm{C}$ adalah 1,80 untuk jagung dan 1,95 untuk kacang tanah.

4. Besarnya rentabilitas usahatani jagung dan kacang tanah per luas lahan garapan adalah $80 \%$ untuk jagung dan $95 \%$ untuk kacang tanah.

\section{Saran}

Berdasarkan dari hasil penelitian ini, yang dapat dikemukakan adalah sebagai berikut:

1. Perlu adanya peran dari pemerintah dan Dinas terkait untuk dapat meningkatkan dan memaksilmalkan produktivitas tanaman pangan palawija sebagai penunjang produksi pangan dengan luasnya lahan hutan yang ada di Cikawung.

2. Petani harus mampu mengatur jadwal penanaman, untuk menghindari panen raya agar harga jual menjadi tinggi dan bisa mendapatkan keuntungan maksimal .

3. Petani harus mampu menjual langsung produknya tanpa harus menjual kepada tengkulak agar mendapatkan keuntungan yang lebih tinggi.

4. Perlu adanya penelitian lagi untuk lebih lanjut agar petani di daerah lain yang tidak memiliki kawasan hutan juga mau dan mampu untuk menanam secara tumpangsari.

\section{Ucapan Terima Kasih}

Ucapan Terimaksih saya ucapkan kepada Fakultas Pertanian dan LPPM UNWIR yang telah membantu dalam penelitian ini, Sehingga penelitiian dengan judul "Efisiensi Usahatani Tumpang Sari Jagung (Zea Mays, L.) dan Kacang Tanah (Arachis Hypogaea, L.) Di Lahan Tanaman Jati (Tectona Grandis, L. F.) Milik Perum Perhutani Pada Kelompok Tani Maju Tani Desa Cikawung Kecamatan Terisi Kabupaten Indramayu, Musim Tanam 2018/2019” dapat terlaksana dengan baik.

\section{DAFTAR PUSTAKA}

Departemen Pertanian. 2012. Road Map Pencapaian Sasaran Produksi Jagung Tahun 2012. [2020 Desember 25]; Jakarta.

Effendi, S.1977. Bercocok Tanam Jagung. Jakarta (ID). CV. Yasaguna. 
Hernanto, F., 1989. Ilmu Usahatani. Jakarta (ID). PT. Penerbit Swadaya.

Jaelani, M. 2018. Analisis Usahatani Kacang Tanah Pada Lahan Perum Perhutani. Indramayu (ID). Fakultas Pertanian Universitas Wiralodra.

Kadarsan, H. W. 2011. Keuangan Pertanian dan Pembiayaan Perusahaan Agribisnis. Jakarta (ID). Gramedia Pustaka Utama.

Kartasapoetra, A.G. 1988. Pengantar Ekonomi Produksi Pertanian. Jakarta (ID). Bina Aksara.

Mosher, A.T. 1984. Menggerakan dan membangun Pertanian. Jakarta (ID). CV. Yasaguna.

Mubyarto, 1989. Pengantar Ekonomi Pertanian. Edisi III. Jakarta (ID). LP3ES.

Nazir, M. 1988. Metode Penelitian. Jakarta (ID). PT. Ghalia Indonesia.

Nedi, B, Supardi, S dan Sutrisno, J, (2013). Analisis Usahatani Jagung di Kabupaten Grobogan Provinsi Jawa Tengah. [2020 Desember 12 ]; Surakarta. Universitas Sebelas Maret

Putri, M. P. 2011. Analisis Komparatif Usahatani Tumpangsari Jagung dan Kacang Tanah dengan Monokultur Jagung. [2020 Desember 23]; Surakarta. Universitas Sebelas Maret Surakarta

Pemerintah Desa Cikawung. 2019. Potensi Desa Cikawung Kecamatan Terisi. [2020 Desember 05]; Indramayu.

Rukmana Rahmat. 2010. Jagung Budidaya, Pascapanen, dan Penganekaragaman Pangan. Aneka Ilmu. CV. Semarang 1.

Singarimbun, M. dan Effendi, S., 2014. Metode Penelitian Survei. Jakarta (ID). LP3ES.

Soeharjo dan Patong. 1973. Sendi - sendi Pokok Usahatani . Departemen Ilmu - ilmu Sosial Ekonomi [Internet]. [2020 Desember 06]; Bogor. Fakultas Pertanian. Institut Pertanian Bogor

Soekartawi, 2002. Ilmu Usahatani dan Penelitian Untuk Pengembangan Petani Kecil. Universitas Indonesia-press [Internet]. [2020 Desember 07]; Jakarta.

Teken, I.B dan Asnawi, 1981. Pengantar Ekonomi Mikro. Jakarta. LP3ES.

Warsana. 2009. Introduksi Teknologi Tumpangsari Jagung dan Kacang Tanah. BPTP Jawa Tengah [Internet]. [2020 Desember 22]; Jawa Tengah.

Widjojo, B. 1983. Analisis Efisiensi Perusahaan. Fakultas Ekonomi Universitas Gajah Mada [Internet]. [2020 Desember 15]; Yogyakarta.

Widya, Yrama. 2009. Budidaya Tanaman Kacang Tanah. Tim Bina Karya Tani [Internet]. [2020 Desember 21]; Bandung.

Wongso, 2010. Agroforestri erosi dan longsor. Pusat Penelitian dan Pengembangan Tanaman Pangan [Internet]. [2020 Desember 22]; Bogor. 